\title{
Self-reported anxiety and depression are unchanged after endoscopic sinus surgery for chronic rhinosinusitis*
}

\author{
Katherine N. Adams ${ }^{1}$, Theodore A. Schuman'2, Charles S. Ebert ${ }^{1}$, Wei You ${ }^{3}$, \\ Mohamed O. Tomoum ${ }^{4}$, Brent A. Senior ${ }^{1}$ \\ ' Department of Otolaryngology, Head and Neck Surgery, University of North Carolina at Chapel Hill, NC, USA \\ 2 Department of Otolaryngology, Head and Neck Surgery, Virginia Commonwealth University School of Medicine, Richmond, VA, \\ USA \\ ${ }^{3}$ Department of Biostatistics, University of North Carolina at Chapel Hill, NC, USA \\ ${ }^{4}$ Department of Otolaryngology, Head and Neck Surgery, Tanta University, Tanta, El-Gharbiya, Egypt
}

Rhinology 56: 3, 234-240, 2018

https://doi.org/10.4193/Rhin17.238

*Received for publication:

November 29, 2017

Accepted: February 27, 2018

Background: Prior research has established that anxiety and depression, as measured by the Hospital Anxiety Depression Score (HADS), are strongly correlated with disease-specific quality of life (Rhinosinusitis Disability Index - RSDI) in chronic rhinosinusitis (CRS). We hypothesized that anxiety and depression would decrease after functional endoscopic sinus surgery (FESS), and furthermore that HADS would predict improvement in RSDI following surgery.

Methodology: The study cohort from 2014 consisted of 99 CRS patients who underwent nasal endoscopy, RSDI, and HADS evaluation. The cohort was segregated by whether or not they underwent FESS and an updated HADS was administered. For 44 surgical patients, pre- and post-operative RSDI $(n=38)$, Lund-Kennedy $(L K)(n=34)$ and HADS $(n=18)$ scores were compared. Delta RSDI was compared between patients with varying levels of anxiety and depression.

Results: Lund-Kennedy scores improved from $5.8 \pm 4.1$ to $3.2 \pm 2.6$ following surgery, as did total RSDI ( $39.3 \pm 26.8$ to $24.6 \pm 29.2$ ). Total HADS (9.8 \pm 6.4 to $11.3 \pm 7.4$ ) and depression and anxiety subscores were unchanged. Linear regression did not reveal a correlation between HADS and change in RSDI following FESS. Delta RSDI was not significantly different between patients with varying levels of anxiety and depression.

Conclusions: Despite improvements in objective evidence of sinonasal inflammation (LK) and disease-specific quality of life (RSDI), neither depression nor anxiety improved after FESS, nor did the magnitude of psychological comorbidity predict postoperative improvement in quality of life. Improvement in RSDI was not different among patients with varying levels of anxiety and depression. Levels of depression and anxiety may be hard-wired, and therefore not influenced by changes in objective or perceived sinonasal disease burden.

Key words: anxiety, depression, chronic rhinosinusitis, quality of life, functional endoscopic sinus surgery

\section{Introduction}

Chronic Rhinosinusitis (CRS) is highly prevalent in the United States, with an estimated 1 to 12.1 percent of the population impacted $^{(1-3)}$. The economic burden of CRS remains high, with direct costs between 10 to 13 billion dollars annually, and indirect costs exceeding 20 billion dollars ${ }^{(3-8)}$. Despite the documented efficacy of medical and surgical therapies for CRS, many patients undergoing aggressive treatment continue to report decreased overall and disease-specific quality of life (QOL) ${ }^{(9)}$. Persistence of subjective symptoms of sinusitis despite radiographic or endoscopic evidence of improved sinonasal inflammation may be influenced by many factors, including mental and physical capabilities ${ }^{(10)}$. Anxiety and depression are prevalent conditions that can influence a patient's perception of the burden of chronic disease states such as CRS, and may furthermore affect the magnitude of improvement after surgical intervention (11). The lifetime prevalence of depression is between 2 to $14 \%$ in the general population but significantly higher in patients with CRS, ranging from 20 to $25 \%$ in this cohort ${ }^{(12-16)}$. This link between depression and CRS is consistent with the more general obser- 
vation that the risk of depression is elevated in patients with chronic disease ${ }^{(13,17-18)}$. Chronically-ill patients with depression have been noted to suffer increased symptom burden, elevated functional impairment, and poorer outcomes after interventions (19-21).

Previously, our group reported the results of a prospective study of 124 patients with CRS who underwent evaluation of anxiety and depression using the Hospital Anxiety and Depression Score (HADS) and also completed a disease-specific QOL questionnaire, the Rhinosinusitis Disability Index (RSDI). The published results of this study revealed a strong correlation between increasing anxiety and depression scores and worsening subjective sinusitis symptoms, despite the fact that objective measurements of sinonasal disease severity were not significantly different between groups. We also noted a high prevalence of depression and anxiety in our CRS population (20\%). These observations support the hypothesis that comorbid anxiety and depression are more common in patients with CRS and may worsen perception of symptoms and QOL ${ }^{(22)}$.

Prior research has established that a majority of patients undergoing surgical intervention for CRS experience improvement in QOL with regards to nasal obstruction, headaches, postnasal drip, hyposmia, and symptoms of asthma ${ }^{(23,24)}$. This QOL improvement after functional endoscopic sinus surgery (FESS) is maintained for at least 3 years in a typical population ${ }^{(25)}$. Despite multiple papers linking psychological comorbidity and impaired QOL in CRS, there remains a paucity of data regarding the interaction between anxiety/depression and changes in QOL following sinus surgery ${ }^{(11,14-16,22,26-29)}$. The current study was designed to better elucidate this relationship through the assessment of HADS and RSDI before and after elective FESS for CRS with and without nasal polyposis.

\section{Materials and methods}

\section{Patients and Methods}

Approval was obtained from the Institutional Review Board at the University of North Carolina at Chapel Hill prior to accessing data from the original prospective study cohort of 124 patients presenting to a tertiary rhinology clinic with symptoms of CRS. Objective nasal endoscopic findings were quantified using the Lund-Kennedy endoscopic score ${ }^{(30)}$; QOL was assessed using the Rhinosinusitis Disability Index (RSDI), a validated diseasespecific instrument ${ }^{(31)}$. Comorbid anxiety and depression were measured using the previously validated Hospital Anxiety and Depression Score (HADS) ${ }^{(32)}$. In this follow up study, the electronic medical records of the original cohort were reviewed, with specific attention as to whether patients underwent FESS since initial enrollment. Telephone contact was attempted with all 124 patients; those consenting to participation in the follow-up study proceeded to HADS and RSDI evaluation over the phone. Since RSDI is routinely obtained at all rhinology clinic visits, some individuals had documented RSDI testing within 6 months and thus only the HADS questionnaire was administered via the phone call. In those patients who underwent FESS since the initial study, a "post-operative" RSDI was included from the 3-9 month postoperative time frame. Pre and post-operative RSDI scores were also noted for any patients who underwent sinus surgery in the one-year time frame before our prior study was initiated. Routine post-operative care for all patients consisted of serial debridement, high-volume saline irrigations, and post-operative antibiotics, guided by culture when appropriate. Further postFESS management was individualized to each patient based upon clinical course and endoscopic evidence of appropriate healing, consistent with the senior author's approaches.

\section{RSDI}

The RSDI is a validated disease-specific QOL instrument consisting of 30 questions designed to measure the impact of CRS in physical, functional, and emotional domains ${ }^{(31,33)}$. Each question is graded on a 0-4 scale, yielding a total possible score ranging from 0 to 120 . Higher scores on the RSDI indicate worse diseasespecific QOL.

\section{HADS}

The HADS is a validated questionnaire consisting of 14 items that the patient rates based on their experience over the past week ${ }^{(32)}$. Half of the questions screen for anxiety and half for depression; these have been found to be independent measures (29). Each question is rated from 0 to 3, giving a total range of 0 to 21 for each domain. Prior research has suggested that a score of 0 to 7 indicates the absence of clinical anxiety or depression, 8 to 10 a possible case of clinical anxiety or depression, and 11 to 21 a certain case of clinical anxiety or depression ${ }^{(32,34,35)}$.

\section{Lund-Kennedy Nasal Endoscopy Score}

This system is designed to quantify objective evidence of sinonasal inflammation observed on nasal endoscopy ${ }^{(36)}$. Individual scores are created for polyps $(0=$ none, $1=$ middle meatus, $2=$ beyond middle meatus), discharge ( $0=$ none, $1=$ clear and thin, $2=$ thick and purulent), edema ( $0=$ absent, $1=$ mild, $2=$ severe), scarring/adhesions ( $0=$ absent, $1=$ mild, $2=$ severe) and crusting ( $0=$ absent, $1=$ mild, $2=$ severe). Combining all sub scores for the right and left nasal cavities yields a total maximum score of 20 .

\section{Statistics}

Data was collected using REDCap electronic data capture tools hosted at the University of North Carolina and analyzed with SAS statistical software ${ }^{(37,38)}$. Descriptive statistics were utilized for demographics. A paired t-test was used to compare the pre- and post-operative scores for the Lund Kennedy, HADS, and RSDI. A chi-squared test was utilized assess whether there was a relati- 
Table 1. Demographics for 99 CRS patients with completed baseline RSDI and HADS.

\begin{tabular}{|lc|}
\hline Characteristic & number (\%) \\
\hline Age, mean (SD), years & $57.4(14.4)$ \\
\hline Follow-up, mean (SD), months & $29.2(0.6)$ \\
\hline Sex, No (\%) & \\
\hline Male & $40(39.2 \%)$ \\
\hline Female & $62(60.8 \%)$ \\
\hline CRS comorbidities, No (\%) of patients & \\
\hline ASA intolerance & $2(1.9 \%)$ \\
\hline Asthma & $31(31.3 \%)$ \\
\hline Nasal Polyps & $42(42.4 \%)$ \\
\hline Allergy & $47(47.5 \%)$ \\
\hline Prior sinus surgery & $49(48 \%)$ \\
\hline OSA & $14(14.1 \%)$ \\
\hline HTN & $29(29.3 \%)$ \\
\hline Heart disease & $12(12.1 \%)$ \\
\hline Diabetes & $9(9.1 \%)$ \\
\hline Thyroid disease & $19(19.2 \%)$ \\
\hline Culmonary disease & $4(4.0 \%)$ \\
\hline Kidney disease & $5(5.1 \%)$ \\
\hline Cancer & $10(10 / 1 \%)$ \\
\hline
\end{tabular}

RSDI= Rhinosinusitis Disability Index; HADS= Hospital Anxiety and Depression Score; $\mathrm{CRS}=$ Chronic Rhinosinusitis; $\mathrm{ASA}$ intolerance= Acetylsalicylic acid intolerance; OSA=Obstructive Sleep Apnea; HTN=Hypertension.

onship between baseline anxiety and depression scores to the following comorbidities: aspirin-exacerbated respiratory disease (AERD), asthma, allergic rhinitis, obstructive sleep apnea (OSA), hypertension, heart disease, diabetes, thyroid disease, pulmonary disease, kidney disease, or cancer. The Kruskal-Wallis and Mann-Whitney $U$ tests were employed to assess for differences in baseline RSDI scores among patients with anxiety and depression scores in the normal (0-7), possible (8-11), and confirmed (12-21) categories. The Kruskal-Wallis test was also utilized to assess for differences in the change in RSDI after FESS among patients with anxiety and depression scores in each category. As there were multiple comparisons in this study, a Bonferroni correction was utilized giving us a significance cutoff of 0.0125 .

\section{Results}

Out of the 124 patients in the original cohort, 25 were excluded due to rhinologic diagnoses other than CRS, including allergic fungal rhinosinusitis, mucocele, cystic fibrosis, autoimmune disease, or sarcoidosis. Ninety-nine patients completed RSDI and HADS testing upon initial study enrollment. The cohort was comprised of $39 \%$ men and $61 \%$ women, with an average age of
$57.4 \pm 14.4$ years. Demographics are listed in Table 1 . Of the 99 CRS patients, 44 (44.4\%) underwent FESS within the study period or in the preceding year. Within this surgical cohort, 35 patients had pre and post-operative RSDI scores recorded and 18 patients had pre and post-operative HADS scores recorded. The post-operative RSDI was administered $27.4 \pm 15.1$ months after baseline RSDI evaluation; post-operative HADS was performed $30.1 \pm 3.4$ months after baseline HADS evaluation.

\section{Baseline anxiety and depression}

Of 99 CRS patients completing RSDI and HADS upon study enrollment between April 2013 and August 2014, 21 (21.2\%) patients scored between 8 and 21 on the anxiety domain of the initial HADS questionnaire, indicating possible or confirmed case of clinical anxiety. Seventeen (17.2\%) patients had a depression score between 8-21, indicating possible or confirmed clinical depression. No significant difference was noted in the prevalence of baseline depression/anxiety in patients that underwent FESS versus those who did not.

A comparison in baseline RSDI scores was completed between patients with varying levels of anxiety and depression. A statistically significant difference was noted in baseline RSDI and domain scores (emotional, functional, and physical) between patients with anxiety scores 0 to 7 (normal), 8 to 11 (possible) and 12 to 21 (confirmed). We found the same trend among depression scores. Patients with "confirmed" anxiety scored $29.2 \pm$ 7.47 points higher on their baseline RSDI than "normal" patients without anxiety. Similarly, patients with "confirmed" depression scored $45.7 \pm 8.35$ points higher on their baseline RSDI than "normal" patients without depression, as shown in Table 2. Chi-squared analysis failed to identify a relationship between the presence of anxiety or depression and comorbidities including aspirin-exacerbated respiratory disease (AERD), asthma, allergic rhinitis, obstructive sleep apnea (OSA), hypertension, heart disease, diabetes, thyroid disease, pulmonary disease, kidney disease, or cancer. Furthermore, HADS did not differ between patients with CRS with or without nasal polyposis.

\section{Anxiety and depression after FESS}

Pre- and post-operative HADS scores were compared in order to assess whether self-reported anxiety or depression changed after surgical intervention for CRS. Among patients who underwent FESS with baseline HADS data, 18 completed a follow-up HADS $24.2 \pm 13.3$ months after surgery. No significant change in total HADS or its anxiety and depression scores were noted after surgery (Table 3). Change in HADS score was also compared between patients who underwent surgery to those who did not, and no significant difference was noted (Table 4).

\section{Change in QOL after FESS}

Thirty-eight patients who underwent FESS completed pre- and 
Table 2. RSDI mean scores in 99 CRS patients with varying levels of anxiety and depression*

\begin{tabular}{|ccccc|}
\hline HADS & Total RSDI & $\begin{array}{c}\text { RSDI } \\
\text { emotional }\end{array}$ & $\begin{array}{c}\text { RSDI } \\
\text { functional }\end{array}$ & $\begin{array}{c}\text { RSDI } \\
\text { physical }\end{array}$ \\
\hline Anxiety & & & & \\
\hline Normal (0-7) & $24.5 \pm 24.2$ & $6.4 \pm 8.0$ & $7.6 \pm 5.8$ & $10.5 \pm 10.0$ \\
\hline $\begin{array}{c}\text { Possible } \\
(8-11)\end{array}$ & $40.8 \pm 34.7$ & $12.3 \pm 11.0$ & $12.9 \pm 10.7$ & $15.8 \pm 14.3$ \\
$\begin{array}{c}\text { Confirmed } \\
(11-21)\end{array}$ & $53.7 \pm 29.6$ & $19.2 \pm 10.8$ & $17.1 \pm 10.5$ & $17.5 \pm 9.8$ \\
\hline $\begin{array}{c}\text { p-value } \\
\text { Depression }\end{array}$ & 0.0038 & 0.0007 & 0.0051 & 0.0519 \\
\hline \begin{tabular}{c} 
Normal (0-7) \\
\hline $\begin{array}{c}\text { Possible } \\
(8-11)\end{array}$
\end{tabular} & $23.2 \pm 22.1$ & $6.1 \pm 7.4$ & $7.1 \pm 7.3$ & $9.9 \pm 9.1$ \\
\hline $\begin{array}{c}\text { Confirmed } \\
(11-21)\end{array}$ & $63.3 \pm 33.6$ & $17.9 \pm 11.5$ & $16 \pm 11.0$ & $19.4 \pm 12.7$ \\
\hline $\begin{array}{c}\text { p-value } \\
\text { (1) }\end{array}$ & 0.0001 & 0.0001 & 0.0001 & 0.0048 \\
\hline
\end{tabular}

RSDI= Rhinosinusitis Disability Index; $C R S=$ Chronic Rhinosinusitis; HADS $=$ Hospital Anxiety and Depression Score, ${ }^{*}$ values are mean \pm SD ** cutoff for significance is 0.0125 .

post-operative RSDI questionnaires, the latter administered 23.3 \pm 12.5 months after surgery. Total RSDI improved following FESS by $14.7 \pm 22.8$ points $(p<0.002)$. Significant improvements in the emotional, functional and physical domains of the RSDI score were also noted after FESS $(p<0.002)$ (Table 3$)$.

\section{Effects of depression and anxiety on QOL improvement after FESS}

The change in RSDI (delta-RSDI) following FESS was computed by subtracting the 3-9 month post-operative RSDI from the baseline pre-operative RSDI score. A higher delta-RSDI thus indicated greater improvement in QOL after surgery. No significant differences were noted in delta-RSDI and its domains among those with normal, possible or confirmed anxiety or depression (Table 5). Anxious and depressed patients thus had a similar QOL improvement after surgery than their non-anxious or depressed counterparts.

\section{Discussion}

Functional endoscopic sinus surgery (FESS) is an effective treatment for CRS refractory to aggressive medical therapy, with a majority of patients reporting increased QOL after surgery, although objective findings of sinus disease correlate poorly with improvement in symptom scores ${ }^{(23,39)}$. Accordingly, patients with improved radiologic or endoscopic findings may continue to report significant symptoms impacting QOL. Psychological factors may contribute to this discrepancy, affecting how pa-
Table 3. Lund Kennedy, HADS and RSDI scores in CRS patients before and after FESS.

\begin{tabular}{|ccccc|}
\hline & n* & $\begin{array}{c}\text { Pre-opera- } \\
\text { tive } \\
\text { (mean SD) }\end{array}$ & $\begin{array}{c}\text { Post-opera- } \\
\text { tive } \\
\text { (mean SD) }\end{array}$ & P-value** \\
\hline Lund Kennedy & 31 & $5.8 \pm 4.1$ & $3.2 \pm 2.6$ & 0.002 \\
\hline HADS Total & 18 & $9.8 \pm 6.4$ & $11.3 \pm 7.4$ & 0.37 \\
\hline Anxiety & 18 & $5.7 \pm 3.7$ & $6.2 \pm 3.3$ & 0.56 \\
\hline Depression & 18 & $4.1 \pm 3.6$ & $5.1 \pm 4.6$ & 0.33 \\
\hline RSDI Total & 38 & $39.3 \pm 26.8$ & $24.6 \pm 29.4$ & 0.0003 \\
\hline Emotional & 38 & $12.2 \pm 10.1$ & $7.6 \pm 10.3$ & 0.0008 \\
\hline Functional & 38 & $2.4 \pm 8.4$ & $8.2 \pm 8.2$ & 0.002 \\
\hline Physical & 38 & $14.7 \pm 10.4$ & $8.7 \pm 10.5$ & 0.0005 \\
\hline
\end{tabular}

HADS= Hospital Anxiety and Depression Score; RSDI= Rhinosinusitis Disability Index; CRS= Chronic Rhinosinusitis; FESS= functional endoscopic sinus surgery. ${ }^{*} \mathrm{n}$ varies based on how many patients had postoperative Lund Kennedy, HADS or RSDI completed. ${ }^{* *}$ cutoff for significance is 0.0125 .

Table 4. Comparison of change in RSDI, HADS and Lund Kennedy scores in surgical and non-surgical CRS patients*.

\begin{tabular}{lccccc} 
& \multicolumn{2}{c}{ No Surgery } & \multicolumn{3}{c}{ Surgery } \\
& $\mathbf{n}$ & Mean \pm SD & $\mathbf{n}$ & Mean \pm SD & p-value** \\
\hline$\Delta$ RSDI & 42 & $-4.1 \pm 18.5$ & 38 & $14.8 \pm 22.8$ & 0.0001 \\
\hline HADS & 23 & $-1.9 \pm 5.9$ & 18 & $-1.4 \pm 6.6$ & 0.81 \\
\hline LKK & 30 & $0.8 \pm 4.0$ & 31 & $2.6 \pm 4.2$ & 0.09 \\
\hline
\end{tabular}

* change calculated by subtracting most recent score from baseline score in non-surgical group, and subtracting 3-9 month post-op score from baseline score in surgical group. RSDI= Rhinosinusitis Disability Index; HADS= Hospital Anxiety and Depression Score; $\mathrm{CRS}=$ Chronic Rhinosinusitis; LK=Lund Kennedy. ${ }^{* *}$ cutoff for significance is 0.0125 .

tients perceive their improvement after an objectively successful procedure.

Prior to surgery, our current study population with possible or confirmed anxiety or depression experienced significantly worse CRS specific QOL than its non-depressed or anxious counterpart. This may be secondary to the fact that chronic sinonasal disease, depression, and anxiety have some degree of overlap with regard to nonspecific symptoms including frustration, sleep disturbances and physical pain.

Several studies have shown that depressed patients with chronic diseases do not experience as much symptomatic relief or QOL improvement after surgery as non-depressed patients $(19,40,41)$. Data regarding the relationship between comorbid depression and symptomatic improvement after surgery for CRS is conflicting. Bransted et al. reported that CRS patients with 
Table 5. Change in RSDI scores before and after surgery in 38 surgical CRS patients with varying levels of anxiety and depression*.

\begin{tabular}{|lcccc|}
\hline HADS & $\begin{array}{c}\Delta \text { Total } \\
\text { RSDI }\end{array}$ & $\begin{array}{c}\Delta \text { RSDI } \\
\text { emotional }\end{array}$ & $\begin{array}{c}\Delta \text { RSDI } \\
\text { functional }\end{array}$ & $\begin{array}{c}\Delta \text { RSDI } \\
\text { physical }\end{array}$ \\
\hline Anxiety & & & & \\
\hline Normal (0-7) & $14.4 \pm 18.8$ & $3.7 \pm 5.4$ & $4.1 \pm 6.8$ & $6.5 \pm 8.9$ \\
\hline $\begin{array}{l}\text { Possible } \\
\text { (8-11) }\end{array}$ & $20 \pm 18.9$ & $5.8 \pm 5.9$ & $7.8 \pm 6.1$ & $6.5 \pm 9.4$ \\
$\begin{array}{l}\text { Confirmed } \\
(11-21)\end{array}$ & $10.5 \pm 38.9$ & $6 \pm 15.0$ & $2.8 \pm 11.5$ & $1.7 \pm 14.1$ \\
\hline p-value & 0.91 & 0.84 & 0.62 & 0.9 \\
\hline $\begin{array}{l}\text { Depression } \\
\text { Normal (0-7) }\end{array}$ & $14.2 \pm 20.3$ & $3.9 \pm 7.3$ & $4.2 \pm 6.2$ & $6 \pm 9.5$ \\
\hline $\begin{array}{l}\text { Possible } \\
\text { (8-11) }\end{array}$ & $6 \pm 15.6$ & $4.5 \pm 4.9$ & $4 \pm 2.8$ & $-2.5 \pm 7.8$ \\
\hline $\begin{array}{l}\text { Confirmed } \\
\text { (11-21) }\end{array}$ & $19.8 \pm 42.0$ & $7.3 \pm 11.9$ & $5 \pm 17.0$ & $7.5 \pm 13.8$ \\
\hline p-value** & 0.49 & 0.68 & 0.46 & 0.3 \\
\hline
\end{tabular}

RSDI= Rhinosinusitis Disability Index; HADS= Hospital Anxiety and

Depression Score; $C R S=$ Chronic Rhinosinusitis. *values are mean \pm SD.

${ }^{* *}$ cutoff for significance is 0.0125 .

depression showed no symptomatic improvement following FESS, whereas CRS patients without depression improved significantly ${ }^{(15)}$. Alternatively, studies by Mace et al., Smith et al., and Litvack et al. reported that depressed patients with CRS have worse pre- and post-operative QOL scores, but do in fact have a similar magnitude in QOL improvement after surgery compared to non-depressed CRS controls ${ }^{(16,27,42)}$. The findings of the current study are in concordance the latter authors' findings, with anxious or depressed patients seeing similar benefit in QOL following FESS despite a worse starting point.

Whereas multiple authors have explored the relationship between depression and QOL in CRS ${ }^{(15,16,27,42)}$, the role of comorbid anxiety in sinus disease is less well studied. The current study demonstrated a lack of concordance between the presence of both anxiety and depression and the magnitude of RSDI improvement after surgery. This may suggest that similar to depression, anxious patients with CRS have significantly decreased disease specific QOL at baseline but experience a similar magnitude of QOL improvement after surgery when compared to a normal patient population. Alternatively, a relationship between depression or anxiety and delta-RSDI may have been obscured by low statistical power or the inherent differences in the two instruments. The RSDI was designed to assess the physical, emotional and social functioning impact that rhinosinusitis has on a patient long term, whereas the HADS comprises statements which the patient rates based on their experience over the past week, meaning that a patients measured anxiety and depression may be expected to change on a weekly basis ${ }^{(31-33)}$.
In addition to exploring the effects of comorbid anxiety and depression on changes in QOL after FESS, the current study sought to assess whether the underlying anxiety/depression itself could improve with surgical modification of the sinonasal inflammatory disease state. Other studies have demonstrated improvement in psychological comorbidity after surgical intervention for separate diseases ${ }^{(43,44)}$. With regard to CRS, Levy et. al utilized the psychological components of the SNOT-22 and found that CRS patients experienced an improvement in "psychologicalrelated symptoms" at about 14 months after sinus surgery ${ }^{(45)}$. Of particular relevance, Litvack et al. reported that CRS patients experienced improvement in depression as measured by the PHQ-9 after sinus surgery ${ }^{(27)}$.

Contrary to these previous findings, patients in the current study did not demonstrate improvement in anxiety or depression after FESS, and in fact trended toward higher HADS scores after surgery, although this finding was not statistically significant. The SNOT-22 was not validated to assess depression or anxiety, so this is likely not an equal comparison ${ }^{(46)}$, although the PHQ-9 does have similar responsiveness and internal reliability as HADS ${ }^{(47,48)}$. The discrepancy may be in part related to the longer time course of the current study; Litvack's patients underwent repeat depression assessment at $13.3 \pm 5.4$ months post-operatively whereas the current study population underwent repeat anxiety/depression assessment at $30.1 \pm 3.4$ months after baseline evaluation. Although further research is needed before definitive conclusions can be made with regard to anxiety and depression and surgical intervention for CRS, the current data may suggest that initial improvements in psychological comorbidity following FESS slowly degrade over the course of several years back to a baseline, "hard-wired" level of anxiety and depression. Interpretation of the current results is tempered by a relatively small sample size due to a reduced response rate within our original published cohort. Additionally, we did not assess whether patients who scored higher on the anxiety and depression questionnaire were undergoing treatment for anxiety or depression. We also did not counsel the patients in any way, or recommend psychological evaluation if they had "confirmed" anxiety or depression based on the HADS.

\section{Conclusion}

It remains unclear whether subsets of CRS patients report higher symptom burden due to comorbid anxiety and depression, or if discomfort from the CRS itself contributes to worsening of psychological angst. Anxiety and depression may become hardwired in CRS patients due to the chronicity of the disease and the emotional, functional and physical toll it takes. Anxiety and depression may contribute to the pathogenesis of the disease as other studies have suggested ${ }^{(49-51)}$. Although the data are preliminary, the longer interval between pre- and post-operative assessment of psychological comorbidity utilized in the current 
study may shed light on the ultimate trajectory of anxiety and depression in patients with CRS. Further research is crucial to better elucidate the natural history of changes in psychological symptoms after FESS; knowledge of these trends would help the surgeon to better predict long-term post-surgical outcomes and to guide interventions in the later post-operative period aimed at improving the patient's wellbeing.

\section{Acknowledgement}

None

\section{Authorship contribution}

KNA: Data collection, analysis, and primary author of manuscript. TAS: Project conceptualization, IRB application, data analysis, manuscript preparation, and oral presentation of results. CSE: Data collection and analysis, manuscript preparation. WY: Data analysis. MOT: Original cohort data collection, analysis, and manuscript preparation. BAS: Project conceptualization, data analysis, manuscript preparation.

\section{Conflict of interest}

No conflicts of interest.

\section{References}

1. Blackwell DL, Lucas JW CT. Summary health statistics for U.S. adults: national health interview survey, 2012. Vital Heal Stat Ser 10, Data from Natl Heal Surv. 2014:1-161.

2. Akkina SR, Novis SJ, Keshavarzi NR, Pynnonen MA. Academic institution pilot study shows far fewer diagnoses of sinusitis than reported nationally. Laryngoscope Investig Otolaryngol. 2016;(Oct):1-6.

3. Bhattacharyya N. Incremental health care utilization and expenditures for chronic rhinosinusitis in the United States. Ann Oto Rhinol Laryngol. 2011;120(7):423-427.

4. Bhattacharyya N, Orlandi RR, Grebner J, Martinson M. Cost Burden of Chronic Rhinosinusitis. Otolaryngol Neck Surg 2011;144(3):440-445.

5. Caulley L, Thavorn K, Rudmik L, Cameron C, Kilty SJ. Direct costs of adult chronic rhinosinusitis by using 4 methods of estimation: Results of the US Medical Expenditure Panel Survey. J Allergy Clin Immunol. 2015;136(6):1517-1522.

6. Bhattacharyya N. Contemporary assessment of the disease burden of sinusitis. Am J Rhinol Allergy. 2009;23(4):392-395.

7. Bhattacharyya N. Functional limitations and workdays lost associated with chronic rhinosinusitis and allergic rhinitis. Am J Rhinol Allergy. 2012;26(2):120-122.

8. Rudmik L, Smith TL, Schlosser RJ, Hwang $\mathrm{PH}$, Mace JC, Soler ZM. Productivity costs in patients with refractory chronic rhinosinusitis. Laryngoscope. 2014;124(9):2007-2012.

9. Wood AJ, Douglas RG. Pathogenesis and treatment of chronic rhinosinusitis. Postgrad Med J. 2010;86:359-364.

10. Wilson IB, Cleary PD. Linking Clinical Variables With Health-Related Quality of Life. JAMA. 1995;273(1):59-65.

11. Wasan A, Fernandez E, Jamison RN, Bhattacharyya N. Association of Anxiety and Depression With Reported Disease Severity in Patients Undergoing Evaluation for Chronic Rhinosinusitis. Ann Otol Rhinol Laryngol. 2007;116(7):491-497.

12. Robins LN, Helzer JE, Weissman MM, et al. Lifetime prevalence of specific psychiatric disorders in three sites. Arch Gen Psychiatry. 1984;41(10):949-958.
13. Katon W, Schulberg H. Epidemiology of Depression in Primary Care. Gen Hosp Psychiatry. 1992;14:237-247.

14. Davis GE, Yueh B, Walker E. Psychiatric distress amplifies symptoms after surgery for chronic rhinosinusitis. Otolaryngol Head Neck Surg. 2005;132:189-196.

15. Brandsted R, Sindwani R. Impact of depression on disease-specific symptoms and quality of life in patients with chronic rhinosinusitis. Am J Rhinol. 2007;21(1):50-54.

16. Mace JC, Michael YL, Carlson NE, Litvack JR, Smith TL. Effects of Depression on Quality of Life Improvement After Endoscopic Sinus Surgery. Laryngoscope. 2008;(118):528-534.

17. Terji SC, Mathers C, Murr CJL. Global burden of depressive disorders in the year. $\mathrm{Br}$ Psychiatry. 2004;184:386-392.

18. Hitchcock Noel P, Williams JW, Worchel J, et al. Depression and Comorbid Illness in Elderly Primary Care Patients : Impact on Multiple Domains of Health Status and Well-being. Ann Fam Med. 2004;2(6):555562.

19. Connerney I, Shapiro PA, Mclaughlin JS Bagiella E, Sloan RP. Relation between depression after coronary artery bypass surgery and 12-month outcome: a prospective study. Lancet. 2001;358:1766-1771.

20. Ciechanowski PS, Katon WJ, D M, et al. The relationship of depressive symptoms to symptom reporting, self-care and glucose control in diabetes. Gen Hosp Psychiatry. 2003:25:246-252

21. Blumenthal JA, Lett HS, Babyak MA, et al. Depression as a risk factor for mortality after coronary artery bypass surgery. Lancet. 2003;362:604-609.

22. Tomoum MO, Klattcromwell C, DelSignore A, Ebert C, Senior BA. Depression and anxiety in chronic rhinosinusitis. Int Forum Allergy Rhinol. 2015;5(8):674-681.

23. Damm M, Quante G, Jungehuelsing M, Stennert E. Impact of Functional Endoscopic Sinus Surgery on Symptoms and Quality of Life in Chronic Rhinosinusitis. Laryngoscope. 2002;112:310-315.

24. Soler ZM, Smith TL. Quality of Life Outcomes after Functional Endoscopic Sinus Surgery. Otolaryngol Clin North Am. 2011:43(3):605-612
25. Khalid AN, Quraishi SA, Kennedy DW Long-Term Quality of Life Measures after Functional Endoscopic Sinus Surgery. Am J Rhinol. 2004;18:131-136

26. Bhattacharyya N, Wasan A. Do anxiety and depression confound symptom reporting and diagnostic accuracy in chronic rhinosinusitis? Ann Otol Rhinol Laryngol. 2008;117(1):18-23.

27. Litvack JR, Mace J, Smith TL. Role of depression in outcomes of endoscopic sinus surgery. Otolaryngol Head Neck Surg. 2011;144(3):446-451.

28. Mace JC, Michael YL, Carlson NE, Litvack JR, Smith TL. Correlations between endoscopy score and quality of life changes after sinus surgery. Arch Otolaryngol Head Neck Surg. 2010;136(4):340-346..

29. Nanayakkara JP, Igwe C, Roberts D, Hopkins C. The impact of mental health on chronic rhinosinusitis symptom scores. Eur Arch Otorhinolaryngol. 2013;270(4):1361-1364.

30. Lund VJ, Kennedy DW, Kingdom U. Staging for rhinosinusitis. Otolaryngol Head Neck Surg. 1997;117:S35-S40.

31. Benninger MS, Senior BA. The development of the rhinosinusitis disability index. Arch Otolaryngol Head Neck Surg. 1997;(123):1175-1179.

32. Zigmond A., Snaith RP. The Hospital Anxiety and Depression Scale. Acta Psychiatr Scand. 1983:67(6):361-370.

33. Senior BA, Glaze C, Benninger MS. Use of the Rhinosinusitis Disability Index (RSDI) in Rhinologic Disease. Am J Rhinol. 2017;15:15-20.

34. Aylard P, Gooding J, McKenna P, Snaith R. A Validation Study of Three Anxiety and Depression Self-Assessment Scales. J Psychosom Res. 1987;31(2):261-268.

35. Hinz A, Brähler E. Normative values for the Hospital Anxiety and Depression Scale (HADS) in the general German population. J Psychosom Res. 2011;71(2):74-78.

36. Lund VJ, Kennedy DW. Quantification for staging sinusitis. Ann Otol Rhinol Laryngol. 1995;(167):17-21.

37. Harris PA, Taylor R, Thielke R, Payne J, Gonzalez N, Conde JG. Research electronic data capture (REDCap)-A metadata-driven methodology and workflow process for 
providing translational research informatics support. J Biomed Inform. 2009:42(2):377381.

38. Stokes ME, Davis CS, Koch GG. Categorical Data Analysis Using the SAS ${ }^{\circledR}$ System, 2nd Edition.; 2012

39. Bhattacharyya N. Radiographic Stage Fails to Predict Symptom Outcomes after Endoscopic Sinus Surgery for Chronic Rhinosinusitis. Laryngoscope. 2006;116(1):18-22.

40. Kamolz T, Granderath FA, Pointner R. Does major depression in patients with gastroesophageal reflux disease affect the outcome of laparoscopic antireflux surgery? Surg Endosc. 2003;17:55-60.

41. Sinikallio S, Aalto T, Airaksinen O, Lehto $\mathrm{S}$, Kroger $\mathrm{H}$, Viinamaki $\mathrm{H}$. Depression Is Associated With a Poorer Outcome of Lumbar Spinal Stenosis Surgery. Spine (Phila Pa 1976). 2011;36(8):677-682.

42. Smith TL, Mendolia-Loffredo S, Loehrl TA Sparapani R, Laud P, Nattinger AB. Predictive Factors and Outcomes in Endoscopic Sinus Surgery for Chronic Rhinosinusitis Laryngoscope. 2005;(115):2199-2205.

43. Ishman SL, Benke JR, Cohen AP, Stephen MJ, Ishii LE, Gourin CG. TRIOLOGICAL SOCIETY Does Surgery for Obstructive Sleep Apnea Improve Depression and Sleepiness?
Laryngoscope. 2014;124:2829-2836.

44. Blackburn J, Qureshi A, Amirfeyz R, Bannister $G$. The Knee Does preoperative anxiety and depression predict satisfaction after total knee replacement? Knee. 2012;19(5):522-524.

45. Levy JM, Mace JC, DeConde AS, Steele TO, Smith TL. Improvements in psychological dysfunction after endoscopic sinus surgery for patients with chronic rhinosinusitis. Int Forum Allergy Rhinol. 2016;6(9):906-913.

46. Hopkins C, Gillett S, Slack R, Lund VJ, Browne JP. Psychometric validity of the 22-item Sinonasal Outcome Test. Clin Otolaryngol. 2009;34(5):447-454.

47. Hansson M, Chotai J, Nordstöm A, Bodlund O. Comparison of two self-rating scales to detect depression: HADS and PHQ-9. $\mathrm{Br}$ Gen Pract. 2009;59(566):650-654.

48. Cameron IM, Crawford JR, Lawton K, Reid IC. Psychometric comparison of PHQ-9 and HADS for measuring depression severity in primary care. $\mathrm{Br} J$ Gen Pract. 2008;58(546):32-36.

49. Ploghaus A, Ploghaus A, Tracey I, et al. Dissociating Pain from Its Anticipation in the Human Brain. Science (80- ). 1999;284(June):1979-1981.

50. Shelton RC. The Molecular Neurobiology of Depression Richard. Psychiatry Clin.
2008;30(1):1-10.

51. Raison $\mathrm{CL}$, Capuron L, Miller AH. Cytokines sing the blues: inflammation and the pathogenesis of depression. Trends Immunol. 2012;27(1):24-31.

\author{
Brent A. Senior, MD \\ Department of Otolaryngology \\ Head and Neck Surgery \\ University of North Carolina Memo- \\ rial Hospitals \\ 170 Manning Dr. \\ Ground Floor Physician Office Buil- \\ ding \\ CB\#7070 Chapel Hill \\ NC 27599
}

USA

Tel: +1-919-966-3342

Fax: +1-919-966-7941

E-mail: bsenior@med.unc.edu 